\title{
Optimal Operation Method for Microgrid with Wind/PV/Diesel Generator/Battery and Desalination
}

\author{
Qingfeng Tang, Nian Liu, and Jianhua Zhang \\ State Key Laboratory of Alternate Electrical Power System with Renewable Energy Sources, North China Electric Power University, \\ Changping District, Beijing 102206, China
}

Correspondence should be addressed to Qingfeng Tang; tangqingfeng523@163.com

Received 23 January 2014; Revised 27 March 2014; Accepted 9 April 2014; Published 16 June 2014

Academic Editor: Hongjie Jia

Copyright (C) 2014 Qingfeng Tang et al. This is an open access article distributed under the Creative Commons Attribution License, which permits unrestricted use, distribution, and reproduction in any medium, provided the original work is properly cited.

The power supply mode of island microgrid with a variety of complementary energy resources is one of the most effective ways to solve the problem of future island power supply. Based on the characteristics of seawater desalination system and water demand of island residents, a power allocation strategy for seawater desalination load, storage batteries, and diesel generators is proposed with the overall consideration of the economic and environmental benefits of system operation. Furthermore, a multiobjective optimal operation model for the island microgrid with wind/photovoltaic/diesel/storage and seawater desalination load is also proposed. It first establishes the objective functions which include the life loss of storage batteries and the fuel cost of diesel generators. Finally, the model is solved by the nondominated sorting genetic algorithm (NSGA-II). The island microgrid in a certain district is taken as an example to verify the effectiveness of the proposed optimal method. The results provide the theoretical and technical basis for the optimal operation of island microgrid.

\section{Introduction}

There has been a long coastline and a large number of islands in China. Safe and reliable power supply is the basic guarantee for the development and construction of the islands and the daily life of the residents. In the past, the islands used to adopt submarine cables or diesel generators for power generation, which leads to frequent breakdowns and serious environmental pollution. Generally, it has abundant renewable energy such as solar energy and wind energy on islands and surrounding regions. With the development of distributed generation and microgrid technologies, the island microgrid could be one of the effective ways to meet the demand of island power supply with a variety of complementary energy resources in future [1-3]. Seawater desalination is one of the main operation modes of water supply. Due to the characteristics of high energy consumption and controllability $[4,5]$, seawater desalination could play a subsidiary role in smoothing the volatility of renewable energy and improving the utilization of clean energy. Therefore, it has important realistic significance to take the controllability of seawater desalination into consideration in the optimal operation of island microgrid.
As to independent microgrids, in [6], the energy supply of microgrid which consisted of photovoltaic, water electrolyzers, proton-exchange membrane fuel batteries, and heat pumps in a cold region is analyzed. The minimum amount of hydrogen and oxygen is taken as the objective function and the paper verifies that the independent microgrid would be more suitable in the matter of operational efficiency as compared to a central system. Reference [7] takes the annual cost of investment and the annual total amount of emissions as target function and optimizes the economic efficiency of power supply and environmental benefits for independent microgrid. A compromise is chosen and the influence of different control strategies to the optimal configuration of independent microgrid is analyzed. In [8], the economic optimization model which includes the cost of equipment, operation and maintenance, fuels, and environmental protection is established. Considering the applying principles and service life of lead-acid batteries, generation cost, total loss cost of batteries, and charging/discharging transformation times of batteries, the nondominated sorting genetic algorithm (NSGA-II) is adopted. Protection and utilization of batteries are focused on in the optimal operation of microgrids. 


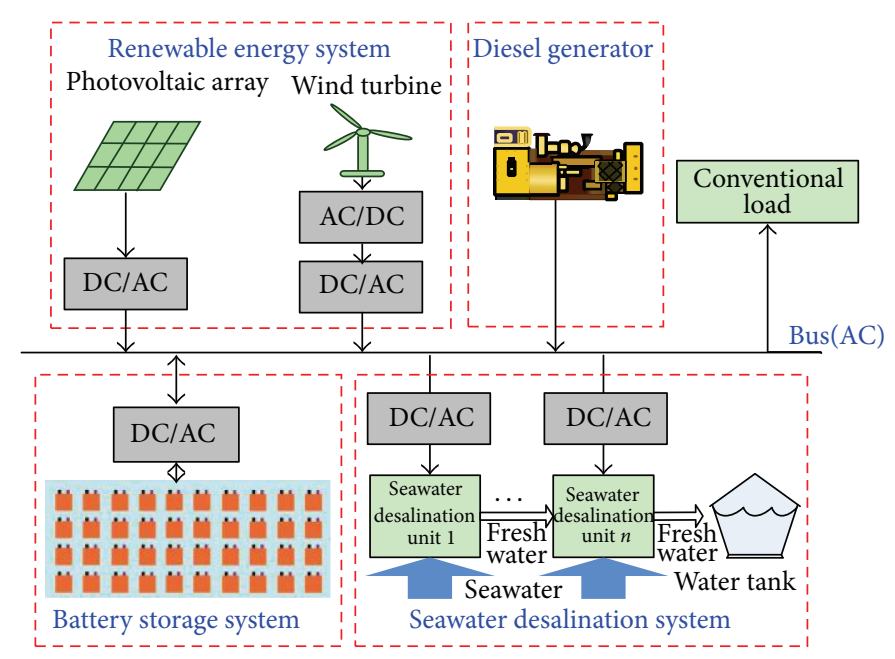

FIGURE 1: Structure of the island microgrid system.

As to independent island microgrid with wind/photovoltaic/diesel/storage and seawater desalination load, in [9], an optimal model which considers the indexes such as whole life cycle, renewable energy utilization, pollutant emission amount, and reliability of power supply is established. The model converts the multiobjective optimization problem to single objective optimization problem by using the linear weighted sum method and provides ideas for multiobjective optimization of distributed generation and storage system. Reference [1] solves the sizing optimization problem with multiple objectives including the minimization of lifecycle cost, the maximization of renewable energy source penetration, and the minimization of pollutant emissions in Dongshan Island, which consists of wind/photovoltaic/storage and seawater desalination load. Due to high precipitation on the island, the seawater desalination system is not often operated.

In the optimization process of island microgrid in the future, the renewable energy generation, controllable power sources, and seawater desalination load would be the typical combination form of island microgrid if the production construction, the need of the residents, environmental, and economic benefits were taken into consideration. Considering the current research situation, even though some research results have been worked out, there are still some problems in two aspects.

Firstly, for the multiobjective process mode of optimal operation, the current research results show that there are multiple objectives of microgrid optimal operation, but most processes are to convert the multiobjective optimization problems to single objective optimization problem $[10,11]$. This kind of method may obtain the reasonable optimization results. Considering that some objectives are mutually exclusive, such as investment cost and renewable energy utilization, consumers need to judge and weigh comprehensively when choosing the final plan, and the solution of single objective is more affirmatory.

Secondly, for the regulation functions of the seawater desalination load, seawater desalination system is used to satisfy the need of water demand. If the unit capacity and storage capacity are suitable, it would be stable and complementary for energy output of intermittent power such as wind/photovoltaic energy.

Therefore, this paper shows the typical structure of island microgrid which consists of wind/photovoltaic/diesel/storage and analyzes the function of each part and then proposes the optimal operation strategy of island microgrid. On this basis, source optimal operation model of island microgrid has been established and solves the problem with the nondominated sorting genetic algorithm (NSGA-II). The operation optimization of independent island microgrid is achieved.

\section{Structure and Function Analysis of Microgrid}

The island microgrid system discussed in this paper mainly consists of photovoltaic generation, wind power generation, diesel generators, an energy storage system, desalination load, and conventional load, as shown in Figure 1.

In an island microgrid system, the photovoltaic and wind power generation systems are uncontrollable micropower source, and they should be scheduled to generate as much power as possible during generation scheduling optimization. As typical controllable load, the desalination system could be used to smooth the volatility of photovoltaic and wind power on the basis of meeting water demand of island residents. The energy storage system can also be used to smooth the volatility of photovoltaic and wind power generation. Moreover, it can cooperate with the diesel generator to ensure the stability of system voltage and frequency. This could better enhance the stability of the microgrid system.

(1) Photovoltaic Generation System. The PV system consists of PV arrays and corresponding DC/AC converter modules. Generally, according to the sunlight condition, the maximum power point tracing (MPPT) control mode is adopted for PV system, which aims to maximize the utilization of solar energy [12]. Let the average PV power output during period $t$ in MPPT control mode be $P_{\mathrm{PV}-M}(t)$. Specially, when the load 
level is extremely low in microgrid system and the PV output is excessive, the $P / Q$ control mode can be adopted, which may lead to decrease or abandonment of $P V$ power. Let the average PV power output during period $t$ in $P / Q$ control mode be $P_{\mathrm{PV}-L}(t)$.

(2) Wind Power Generation System. Generally, there are three types of wind turbines in a wind power generation system: fixed speed induction generator (FSIG), permanent magnet synchronous generator (PMSG), and doubly fed induction generator (DFIG). MPPT control mode is adopted for PMSG and DFIG according to wind speed condition [13], while the output of a single FSIG is uncontrollable. Let the average wind power output during period $t$ in such scenario be $P_{\mathrm{WG}-M}(t)$. Specially, when the load level is extremely low in microgrid system and the wind power is excessive, the $P / Q$ control mode can be adopted for PMSG and DFIG. Moreover, part of the FSIG can be cut out to reduce the wind power output, which will lead to abandonment of wind power. Let the average wind power output during period $t$ in such scenario be $P_{\mathrm{WG}-L}(t)$.

(3) Energy Storage System. In the microgrid system, energy storage system usually consists of Li-ion batteries or lead-acid batteries and bidirectional AC/DC converters. The energy storage system can be in charging or discharging status in different renewable power generation and load situations $[14,15]$. During the charging process, the AC/DC converter can operate in $V / f$ or $P / Q$ control mode. Let the average charging/discharging power during period $t$ be $P_{\text {bat }}(t)$, where $P_{\text {bat }}(t)<0$ when charging and $P_{\text {bat }}(t)>0$ when discharging.

(4) Diesel Generator. Diesel generators are the main power sources in island power system. The energy storage system in microgrid can operate in $V / f$ control mode, but only single $V / f$ source is permitted when microgrid is in isolated operation. Therefore, to better utilize the reserve function of diesel generators and the energy storage system, $V / f$ and $P / Q$ two control modes are adopted as the operation modes of diesel generators. Let the average power output of diesel generators during period $t$ be $P_{\text {die }}(t)$.

(5) Desalination System. The seawater desalination system consists of several desalination units and reservoirs [5]. Let $N_{\text {des }}$ be the number of desalination units. Set $P_{\text {des }}, G_{\text {des }}$ as the rated power of single desalination unit and water yield per hour. The desalination system can be turned on or off according to water demand. Let the load of desalination system during period $t$ be $P_{\text {des }}(t)$, which satisfies $0 \leq P_{\text {des }}(t) \leq$ $N_{\text {des }} P_{\text {des }}$.

\section{Energy Exchange Strategy of Microgrid}

3.1. Regulation Strategy of Seawater Desalination Load. The seawater desalination load is considered as controllable load, which could help to adjust system power output. According to the water demand of island residents, reservoir volume, and the number of desalination units, the upper and lower bounds of desalination load per hour can be calculated. Let
$N_{\text {des-min }}(t), N_{\text {des-max }}(t)$ be the upper and lower limit of the number of desalination units that can be turned on during period $t$. Similarly, let $P_{\mathrm{des}-\min }(t), P_{\mathrm{des}-\max }(t)$ be the upper and lower limit of the desalination load during period $t$. Let $R_{\text {water }}(t)$ be the water demand during period $t$. $R_{\text {des - max }}$ represents the maximum water volume of the reservoir at the end of period $t . R_{\text {des-min }}$ represents the minimum water volume of the reservoir for emergency. $N_{\text {des }}$ represents the number of desalination units.

(1) The lower limit of desalination load is determined by the minimum water volume of the reservoir, current water demand, and current water volume of the reservoir.

(a) The current water volume is sufficient:

$$
R_{\text {des }}(t-1)-R_{\text {des }- \text { min }} \geq R_{\text {water }}(t) .
$$

The current water volume can meet the water demand and the remaining water is higher than the minimum water volume of the reservoir. All the desalination units can be turned off:

$$
N_{\text {des-min }}(t)=0 .
$$

(b) The current water volume is insufficient:

$$
R_{\text {des }}(t-1)-R_{\text {des }- \text { min }}<R_{\text {water }}(t) .
$$

The units to be turned on should be determined according to the vacancy of water volume:

$$
N_{\text {des }- \text { min }}(t)=\left\lceil\frac{R_{\text {water }}(t)-\left(R_{\text {des }}(t-1)-R_{\text {des }- \text { min }}\right)}{G_{\text {des }}}\right\rceil .
$$

(2) The upper limit of desalination load is determined by the maximum water volume of the reservoir, current water demand, and current water volume of the reservoir.

(a) The current water volume is low. When satisfying the current water demand and turning on all the units, the upper limit of water reservoir still cannot be reached:

$$
R_{\text {des }}(t-1)+N_{\text {des }} P_{\text {des }}-R_{\text {water }}(t) \leq R_{\text {des }-\max } \text {. }
$$

All the units should be turned on:

$$
N_{\text {des-max }}(t)=N_{\text {des }} \text {. }
$$

(b) The current water volume is low. When satisfying the current water demand and turning on all the units, the upper limit of water reservoir will be reached:

$R_{\text {des }}(t-1)+N_{\text {des }} P_{\text {des }}-R_{\text {water }}(t)>R_{\text {des }-\max }$.

Some of the units should be turned on under the premise that the water would not exceed the upper limit of the water reservoir:

$$
N_{\text {des-max }}(t)=\left\lfloor\frac{R_{\text {des }- \text { max }}+R_{\text {water }}(t)-R_{\text {des }}(t-1)}{P_{\text {des }}}\right\rfloor .
$$


Moreover, the desalination load upper and lower limit can be determined according to the maximum and minimum number of desalination units in each time period:

$$
\begin{aligned}
& P_{\text {des-max }}(t)=N_{\text {des }- \text { max }}(t) \times P_{\text {des }}, \\
& P_{\text {des }- \text { min }}(t)=N_{\text {des }- \text { min }}(t) \times P_{\text {des }} .
\end{aligned}
$$

The power regulation function of desalination system is as follows: when solar and wind energy is sufficient, the desalination units should be turned on as many as possible to utilize more renewable energy. When solar and wind energy is insufficient, the desalination units should be turned off as many as possible to provide relief for diesel generators and energy storage system.

3.2. Regulation Strategy of Battery. If the system power balance cannot be achieved by adjusting desalination system, the battery charging/discharging power should be adjusted.

According to state of charge and the rated power limit of battery charging and discharging machine, the upper and lower limit of the battery output during each time period can be calculated to determine the regulating range of the battery. Let $P_{c-\max }(t), P_{d-\max }(t)$ be the maximum charging and discharging power during period $t$; $\operatorname{Soh}(t)$ represents the status of battery during period $t$. Soh max $_{\text {man }}$, Soh $h_{\min }$ represents the upper and lower limit of battery power. $C_{d N}$ represents the rated capacity of the battery and $P_{c}$ represents the rated power of the charging/discharging machine:

$$
\begin{aligned}
& P_{c-\text { max }}(t)=\min \left(C_{d N} \times\left(\operatorname{Soh}_{\max }-\operatorname{Soh}(t)\right), P_{c}\right), \\
& P_{d-\max }(t)=\min \left(C_{d N} \times\left(\operatorname{Soh}(t)-\operatorname{Soh}_{\text {min }}\right), P_{c}\right) .
\end{aligned}
$$

The power regulation function of the battery is as follows: when the power output of renewable energy is high, it can be used to charge the battery and make use of the excessive energy that cannot be fully used by desalination system; when the power output of renewable energy is low, the battery can be set to discharge to meet the load demand of microgrid.

3.3. Regulation Strategy of Diesel Generator. If the system power balance still cannot be achieved by adjusting desalination system and battery output, the diesel generator output should be adjusted.

To ensure the operating temperature and prolong the service life of the generator, the minimum power output of the diesel generator should be $30 \%$ of its rated power. Let the rated power of the diesel generator be $P_{d} . P_{\text {die }}(t)$ represents the output during period $t$; then the output range of diesel generators is

$$
P_{\text {die } \min } \leq P_{\text {die }}(t)<N_{\text {die }} P_{d}
$$

where $P_{\text {die-min }}$ is the lower output limit of the generator.

The power regulation function of the diesel generator is as follows: when the renewable energy is extremely insufficient, the load demand in the microgrid system can be met by turning on diesel generators to balance the power in the system.
3.4. Energy Exchange Model of Island Microgrid. Diesel generators, batteries, and desalination load are controllable to some extent. Considering the economic efficiency and utilization of renewable energy, in the real operation, the desalination load is first scheduled and then the battery charging/discharging power is adjusted. Finally, the diesel generator output adjustment is done to maintain system power balance.

Let $P_{\text {net }}(t)$ be the vacancy between wind, solar power output, and conventional load during period $t$ :

$$
P_{\text {net }}(t)=P_{\mathrm{WG}-M}(t)+P_{\mathrm{PV}-M}(t)-P_{l}(t),
$$

where $P_{\mathrm{WG}-M}, P_{\mathrm{PV}-M}(t), P_{l}(t)$ are separately the wind power output, PV output, and conventional load during period $t$.

Comparing net power $P_{\text {net }}(t)$ with the upper and lower limit of desalination load $P_{\text {des - min }}(t), P_{\text {des-max }}(t)$, three possible situations can be obtained.

(1) The net power is less than or equal to the lower limit of desalination load:

$$
P_{\text {net }}(t) \leq P_{\text {des }-\min }(t)
$$

The basic water demand should be met:

$$
P_{\mathrm{des}}(t)=P_{\mathrm{des}}-\min (t) .
$$

The net load is insufficient for the desalination units, so the batteries and diesel generators should be adopted to meet load demand. Specifically, the maximum discharging power is first determined by the rated capacity of the battery, state of charge (SOC), and discharging depth. The vacancy should be supplied by diesel generators.

Let $P_{d f}(t)$ be the vacancy between wind, PV power, conventional load, and desalination load:

$P_{d f}(t)=P_{\mathrm{WG}-M}(t)+P_{\mathrm{PV}-M}(t)-P_{l}(t)-P_{\mathrm{des}}(t)$.

(a) If the vacancy is less than the maximum discharging power of the battery,

$$
P_{d f}(t) \leq P_{d-\max } .
$$

Discharging power output of battery during period $t$ is $P_{b}(t)$, which is equal to the vacancy $P_{d f}(t)$, and the diesel generator will not be started.

(b) If the vacancy is more than the maximum discharging power of the battery,

$$
P_{d f}(t)>P_{d-\max }
$$

The battery operates in the highest discharging rate. The diesel generator needs to be started and its power output is determined by the remaining power vacancy. 
(i) If the remaining power vacancy is more than the minimum output limit of diesel generators,

$P_{d f}(t)-P_{b}(t) \geq P_{\text {die } \min }=0.3 \times P_{d}$.

The output of diesel generator $P_{\text {die }}(t)$ should be

$$
P_{\text {die }}(t)=P_{d f}(t)-P_{b}(t) .
$$

(ii) If the remaining power vacancy is less than the minimum output limit of diesel generator,

$P_{d f}(t)-P_{b}(t) \geq P_{\text {die } \cdot \min }=0.3 \times P_{d}$.

The output of the diesel generator is its minimum power output limit, and in this paper it is 30\% of its rated power, that is, $0.3 * P_{d}$. Excessive power generated by diesel generators can be balanced by battery or by abandoning wind or solar energy.

(2) The net power is more than the lower limit of desalination load and less than the upper limit of desalination load:

$$
P_{\text {des }- \text { min }}(t)<P_{\text {net }}(t)<P_{\text {des }-\max }(t) .
$$

The number of desalination units $n$ that could be turned on can be determined by net power level:

$$
n=\left\lfloor\frac{P_{\text {net }}(t)}{P_{\text {des }}}\right\rfloor, \quad\left(0 \leq n \leq N_{\text {des }}\right) \text {. }
$$

Correspondingly, the output of desalination units is

$$
P_{\text {des }}(t)=n P_{\text {des }} \text {. }
$$

The net load still has some vacancy, which can be absorbed by battery:

$$
P_{b}(t)=P_{\text {net }}(t)-P_{\text {des }}(t) .
$$

If the battery cannot meet the charging condition, these vacancies should be abandoned. The diesel generators do not need to be started.

(3) The net power is more than the upper limit of desalination load:

$$
P_{\text {net }}(t)>P_{\text {des }-\max }(t) \text {. }
$$

To utilize as much renewable energy as possible, the desalination units operate at full power rate:

$$
P_{\text {des }}(t)=P_{\text {des }-\max }(t) \text {. }
$$

The net load still has some vacancies, which can be absorbed by the battery:

$$
P_{\text {bat }}(t)=P_{\text {net }}(t)-P_{\text {des }}(t) \text {. }
$$

If the battery cannot meet the charging condition, these vacancies should be abandoned. The diesel generators do not need to be started.

The aim of such strategy is to reduce the operating time of diesel generators, and the detailed operating flowchart is shown in Figure 2.

\section{Optimization Model of Microgrid with Wind/Photovoltaic/Diesel/Storage and Seawater Desalination Load}

4.1. Objective Function. In the dispatching model of microgrid which consists of wind, solar, diesel generator, and desalination load proposed in this paper, the objective is to minimize the life loss of batteries and minimize the fuel cost of diesel generators.

(1) Model to Minimize the Life Loss of Batteries. The lead-acid battery is served as an energy storage system. The relationship between the cycle service life of the lead-acid battery and its discharging depth can be represented by a linear function [16]:

$$
L=a D+b
$$

where $a, b$ are $-4775,4955$, respectively; $L$ is the cycle service life time of the battery; $D$ is the discharging depth.

The relationship between the accumulated service life of lead-acid battery and its discharging depth can be seen from the relationship between its effective weighted factor (EWF) and its SOC. It is shown in Figure 3.

When the SOC value is 0.5 , that is, the discharging depth of the battery is 0.5 , the EWF is 1.3 , which means the battery service life will add $1.3 \mathrm{Ah}$ when it discharges $1 \mathrm{Ah}$ [8].

Suppose the service life loss factor of the battery is $\lambda$; then the relationship between cycle service life time and discharging depth can be represented by the following piecewise function:

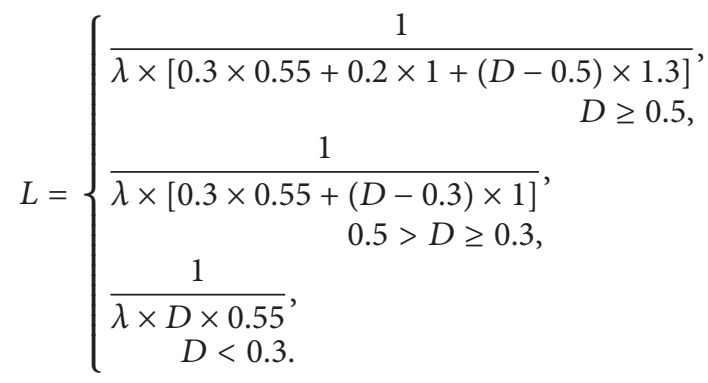

If the discharging depth is given, the service lifetime $L$ can be calculated from (28); then from (29), the service life loss factor $\lambda$ can be calculated. From the initial discharging depth $D_{c}$, the final discharging depth $D$ and (28) the service life loss of the battery $S_{h}$ can be obtained.

(a) When the initial discharging depth $D_{c} \leq 0.3$.

(i) When the final discharging depth $D \leq 0.3$,

$$
S_{h}=\frac{1}{L}=\left(D-D_{c}\right) \times 0.55 \times \lambda \text {. }
$$

(ii) When the final discharging depth $0.3<D \leq 0.5$,

$$
S_{h}=\frac{1}{L}=\left[\left(0.3-D_{c}\right) \times 0.55+(D-0.3) \times 1\right] \times \lambda .
$$




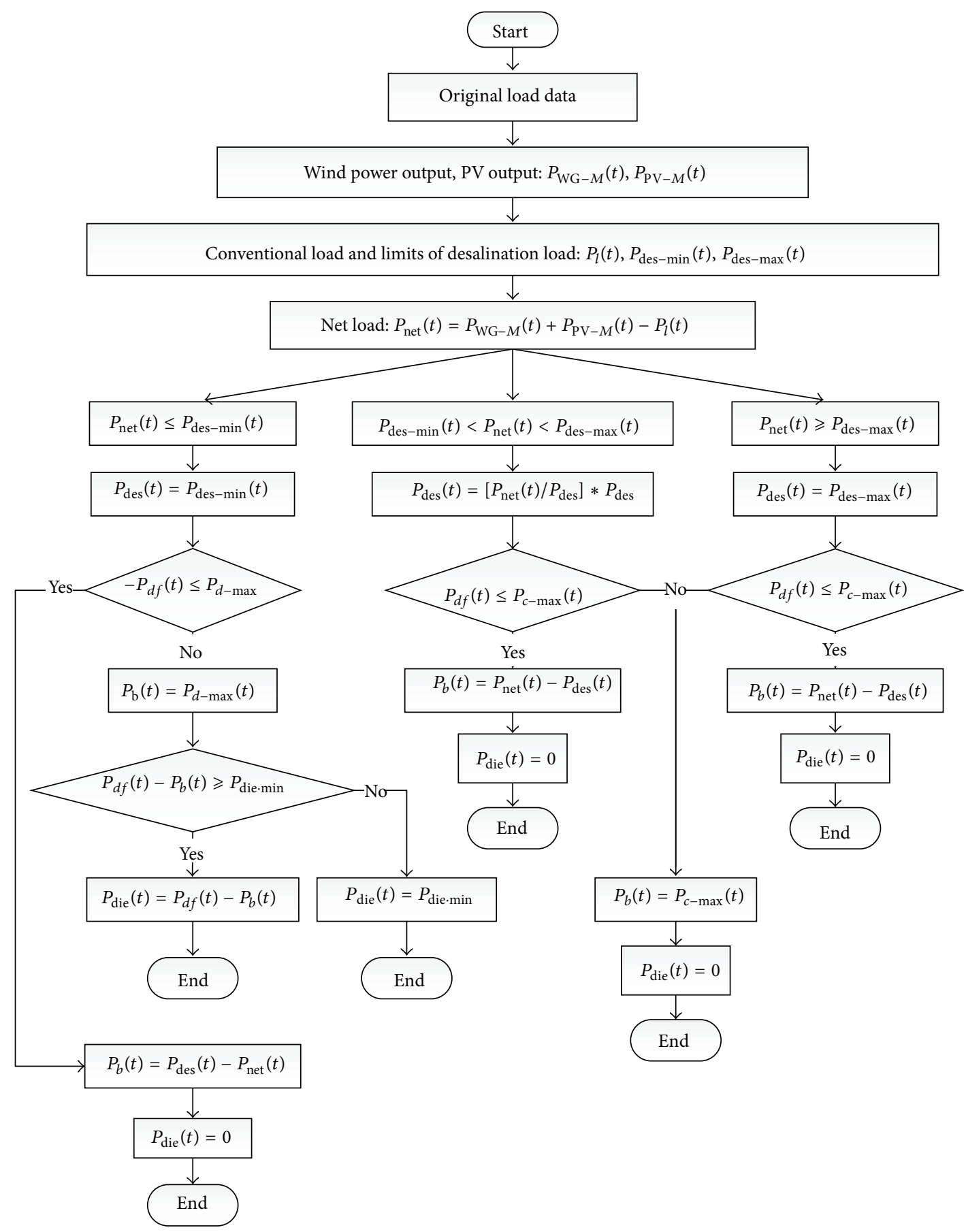

FIgURE 2: The flowchart of energy exchange strategy in island microgrid.

(iii) When the final discharging depth $D>0.5$, $S_{h}=\frac{1}{L}=\left[\left(0.3-D_{c}\right) \times 0.55+0.2 \times 1+(D-0.5) \times 1.3\right] \times \lambda$.

(b) When the initial discharging depth $0.3<D_{c} \leq 0.5$.

(i) When the final discharging depth $0.3<D \leq 0.5$,

$$
S_{h}=\frac{1}{L}=\left(D-D_{c}\right) \times 1 \times \lambda .
$$

(ii) When the final discharging depth $D>0.5$,

$$
S_{h}=\frac{1}{L}=\left[\left(0.5-D_{c}\right) \times 1+(D-0.5) \times 1.3\right] \times \lambda
$$

(c) When the initial discharging depth $D_{c}>0.5$,

$$
S_{h}=\frac{1}{L}=\left(D-D_{c}\right) \times 1.3 \times \lambda .
$$




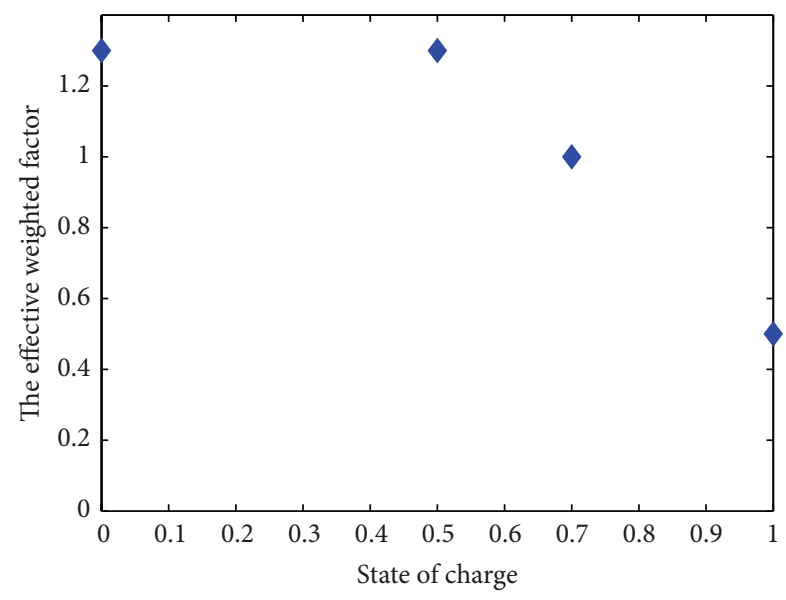

FIGURE 3: The relationship between EWF and SOC of lead-acid battery.

The objective function is

$$
F_{1}=\min \sum_{n=1}^{N_{d}}\left(S_{h}(n)\right)
$$

where $S_{h}(n)$ is the service life loss during the $n$th discharging cycle.

(2) Model to Minimize Fuel Cost of Diesel Generators. The objective function is

$$
F_{2}=\min \sum_{t=1}^{24}\left(P_{\text {die }}(t) \times C_{f} \times C_{p}\right),
$$

where $P_{\text {die }}(t)$ is the power output of diesel generators during period $t ; C_{f}$ is the diesel oil consumed to generate unit power; $C_{p}$ is the cost of each unit of the diesel oil.

From another perspective, to minimize the fuel cost of diesel generators is another way to improve the utilization of renewable energy. This is because that in the microgrid system with photovoltaic generation, wind power generation, diesel generators, and an energy storage system, the main power source is the wind, solar renewable power generation system, and the diesel generators. When the fuel cost of diesel generators decreases, the output of diesel generator decreases as well. This will increase the proportion of renewable energy in the whole system and improve the utilization of renewable energy.

\subsection{Constraints}

(1) The power output constraints of diesel generators are as follows:

$$
0.3 \times P_{d} \leq P_{\text {die }}(t) \leq P_{d},
$$

where $P_{d}$ is the rated power of diesel generators. For real diesel generators, there is a lower limit during its operation. In this paper, it is set to be $30 \%$ of its rated power.
(2) System power balance constraints are as follows:

$$
P_{\mathrm{WG}}(t)+P_{\mathrm{PV}}(t)+P_{\mathrm{bat}}(t)+P_{\mathrm{die}}(t)=P_{l}(t)+P_{\mathrm{des}}(t),
$$

where $P_{l}(t), P_{\text {des }}(t), P_{\mathrm{WG}}(t), P_{\mathrm{PV}}(t), P_{\text {die }}(t), P_{\text {bat }}(t)$ are, respectively, the conventional load, desalination load, wind power output, PV output, diesel generator output, and battery output. $P_{b}$ is positive when discharging and negative when charging.

(3) Battery charging/discharging constraints are as follows:

$$
P_{c-\max } \leq P_{b}(t)+P_{d-\max },
$$

where $P_{d-\max }$ is the maximum output when the battery is discharging; $P_{c-\max }$ is the maximum output when the battery is charging.

(4) Battery capacity constraint is as follows:

$$
\operatorname{Soh}_{\text {min }} \leq \operatorname{Soh}(t) \leq \text { Soh }_{\text {max }},
$$

where $\mathrm{Soh}_{\min }$ and $\mathrm{Soh}_{\max }$ are the minimum and maximum value of the SOC of the battery; $\operatorname{Soh}(t)$ is the SOC of the battery during period $t$.

(5) Desalination units number constraints are as follows:

$$
N_{\text {des }-\min }(t) \leq N_{\text {des }}(t) \leq N_{\text {des }- \text { max }}(t) .
$$

\section{Model Solution}

According to the model of optimal operation, the problem can be expressed as follows:

$$
\begin{array}{ll}
\min & \mathbf{Y}=\min [C, \text { PODG }] \\
& =\min \left\{F_{1}, F_{2}\right\} \\
\text { s.t. } & h_{j}(\mathbf{u}, \mathbf{x})=0, \quad j=1,2, \ldots, p \\
& g_{j}(\mathbf{u}, \mathbf{x}) \leq 0, \quad j=1,2, \ldots, q \\
& u_{i \min } \leq u_{i \min } \leq u_{i \max }, \quad i=1,2, \ldots, n,
\end{array}
$$

where $\mathbf{Y}$ is the vector of objective function, $\mathbf{u}$ and $\mathbf{x}$ are control variables and state variables, respectively, $h$ and $g$ are equality constraints and inequality constraints, respectively, and $n$ is the dimension of the parameter control vector.

The solution procedure of multiobjective optimization model proposed in this paper is essentially a nonlinear optimization problem which contains multiple decision variables, and the model is solved by the nondominated sorting genetic algorithm (NSGA-II). NSGA-II was put forward by Deb and so forth and is modified based on the algorithm of NSGA in 2002 [17]. It is a multiobjective optimization algorithm with high recognition. Comparing to the original NSGA algorithm, the major advantages are shown as follows.

(1) The fast nondominated sorting method based on classification is employed, and its computational complexity is $O\left(m N^{2}\right), m$ is the number of objective function, and $N$ is the number of individuals in population. 


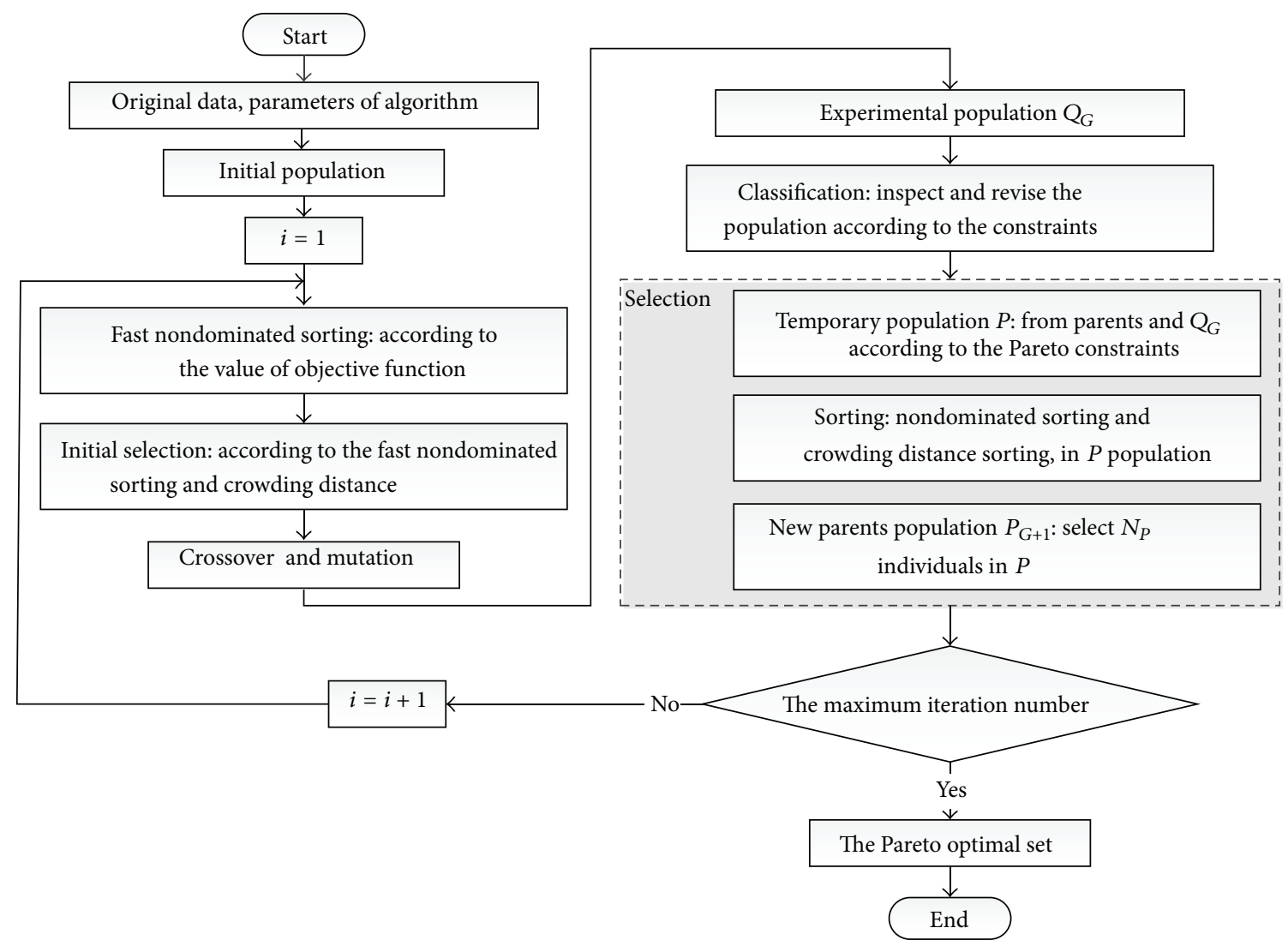

FIGURE 4: The process of the power allocation strategy by NSGA-II.

(2) The notion of crowding distance is proposed to show the fitness value of different elements in the same level after fast nondominated sorting procedure to ensure that the individuals in Pareto front can expand the scope of Pareto frontier evenly; $O(m(2 N) \log (2 N))$ is the time complexity of crowding distance.

(3) The mechanism of the elite reservation is introduced. The new generation is created by the competition between the offspring individuals and the parent individuals. This mechanism can improve the overall level of evolutionary population. Specific process is shown in Figure 4.

\section{Simulation Results}

6.1. Basic Data. The system studied in this paper is an independent island microgrid system with wind/photovoltaic/diesel/storage and seawater desalination load on an island in China. The parameters of each component in the system are given in Table 1.

In addition, the maximum electricity load is $300 \mathrm{~kW}$, and daily water demand is about 500 tons on the island. Eight seawater desalination machines compose the desalination system. The rated power of each machine is $25 \mathrm{~kW}$ and the rated daily water production is 100 tons. The maximum

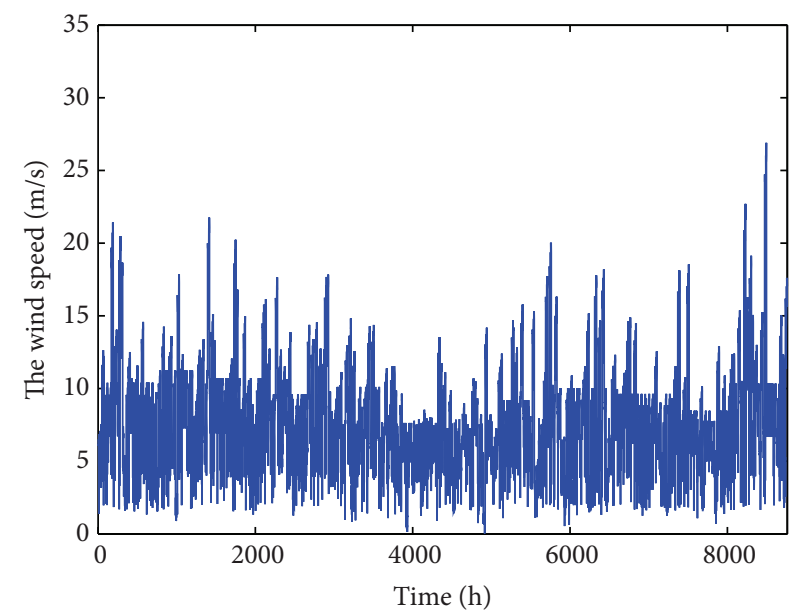

FIgURE 5: The speed distribution of the wind.

reservoir capacity of the system is 160 tons, and the minimum water requirement is 48 tons.

The data about wind, solar radiation, the conventional load in winter and summer, and the water demand is shown in Figures 4, 5, 6, and 7.

The annual mean wind speed is about $10 \mathrm{~m} / \mathrm{s}$ at the height of 90 meters on the island, which is influenced by the coastal 


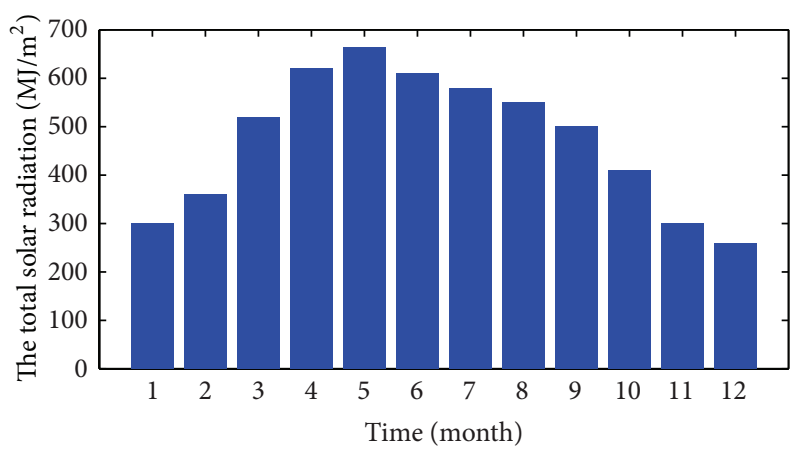

FIGURE 6: The annual radiation data.

TABLE 1: Parameters of each component.

\begin{tabular}{lc}
\hline Components & Parameters \\
\hline Photovoltaic battery capacity/kW & 285 \\
Wind power capacity/kW & 350 \\
Storage battery capacity/kWh & 300 \\
The maximum charge/discharge power of storage & 100 \\
battery/kW & 300 \\
Diesel generator rated power/kW & \\
\hline
\end{tabular}

TABLE 2: The extreme solution of Pareto optimal concentration considering the effect of auxiliary power regulation.

\begin{tabular}{lcc}
\hline & $\begin{array}{c}\text { Storage battery life } \\
\text { loss }\end{array}$ & $\begin{array}{c}\text { Diesel fuel } \\
\text { consumption/RMB }\end{array}$ \\
\hline $\begin{array}{l}\text { The minimum of storage } \\
\text { battery life loss }\end{array}$ & 0 & 4021 \\
$\begin{array}{l}\text { The minimum of diesel } \\
\text { generator fuel } \\
\text { consumption }\end{array}$ & 0.0012 & 3230 \\
\hline
\end{tabular}

air current. Higher wind velocity appears in winter and in summer the speed is relatively low.

The monthly variation range of total solar radiation is $260 \mathrm{MJ} / \mathrm{m}^{2}-663 \mathrm{MJ} / \mathrm{m}^{2}$. The summit appears in April and May, and the highest value achieves $663 \mathrm{MJ} / \mathrm{m}^{2}$ in May. The trough value of radiation appears from November to January of the next year, and the lowest value achieves $260 \mathrm{MJ} / \mathrm{m}^{2}$ in December. The annual solar radiation is about $5695 \mathrm{MJ} / \mathrm{m}^{2}$, which means the solar energy on the island has great development potential.

The total daily water consumption of residents is about 500 tons, the peak period is 9:00 a.m. and 7:00 p.m. The maximum of daily water demand achieves 22.8 tons at 7:00 p.m. and the minimum value is 16.3 tons.

6.2. The Optimization Results Analysis of Seawater Desalination System Considering the Effect of Auxiliary Power Regulation. The population quantity is 200 . The maximum iterations are 5000 in optimization procedure. The crossover rate is 0.3 . The mutation rate is 0.5 . The optimization results and the extreme solution of Pareto are shown in Figure 8 and Table 2.
From Figure 8 and Table 2, it can be seen that the objective of storage battery life loss and diesel generators fuel consumption is conflicted mutually. It is adverse for reducing the fuel consumption of diesel generator when selecting the solution of minimizing storage battery life loss. If the fuel consumption is taken as sole objective, it will lead to higher life loss of storage battery.

From Figure 8, it can be seen that the relevance orientation of Pareto optimal set can be divided into two parts: in the first part, with the increasing of the diesel fuel consumption, the storage battery life loss decreases significantly; in the second part, the Pareto optimal set gets more gentle when the storage battery life loss tends to be 0 . The statistics show that when the storage battery life loss tends to be 0 , reducing the storage battery life loss is at the expense of high fuel consumption during optimal operation. It is not economical.

In Figure 8, the Pareto optimal set shows that the different life loss value will lead to different fuel consumption; namely, the different charge/discharge conditions of battery have the different operational conditions of the diesel generators. In actual operation, according to the requirements of life loss or diesel generator, the optimal output power of island microgrid system with wind/photovoltaic/diesel/storage can be determined.

Life loss expenses are converted into loss expenses in order to reflect the economic efficiency of optimal solution in general, and the loss expense of battery is

$$
S_{F}=F_{1} \times M,
$$

where $S_{F}$ and $M$ are the loss expenses and the total investment cost of the storage battery.

Total loss expense of system operation consists of two parts: the expenses of storage batteries life loss and the fuel consumption of diesel generators:

$$
C=S_{F}+F_{2}
$$

where the total investment cost of the storage battery is RMB 30 million and the total loss expenses are shown in Table 3. To compare the results of considering auxiliary power regulation of seawater desalination load and the results without auxiliary power regulation, Table 3 shows the extreme solutions under the two cases.

Considering auxiliary power regulation of seawater desalination load, the extreme solution is superior over the condition without auxiliary power regulation. From the overall economic point of view, both the value of life loss and fuel consumption become lower than the condition without auxiliary power regulation at the minimum of total loss expenses, and the total expenses are also lower. The reduction of fuel consumption enhances the renewable energy utilization. Auxiliary power regulation of seawater desalination load significantly increases the operating economic efficiency and renewable energy utilization of island microgrid.

A suitable solution from Pareto front is selected to get the output results of the various microsources in 24 hours at the minimum of total loss expenses. The output results are shown in Figure 9, where the renewable energy output is the sum of wind power and photovoltaic power. 
TABLE 3: Parameters comparison of seawater desalination load considering auxiliary power regulation and without auxiliary power regulation.

\begin{tabular}{lcc}
\hline Parameters & $\begin{array}{c}\text { Considering auxiliary power } \\
\text { regulation }\end{array}$ & $\begin{array}{c}\text { Not considering auxiliary } \\
\text { power regulation }\end{array}$ \\
\hline The minimum of storage battery life loss & 0 & 0 \\
The maximum of diesel generator fuel consumption/RMB & 4021 & 4507 \\
The maximum of storage battery life loss & 0.0012 & 0.0015 \\
The minimum of diesel generator fuel consumption/RMB & 3230 & 3924 \\
The minimum of total loss expenses/RMB & 3576 & 4357 \\
Storage battery life loss in minimum total loss expenses & 0.0011 & 0.0014 \\
Fuel consumption in minimum total loss expenses/RMB & 3256 & 3947 \\
\hline
\end{tabular}

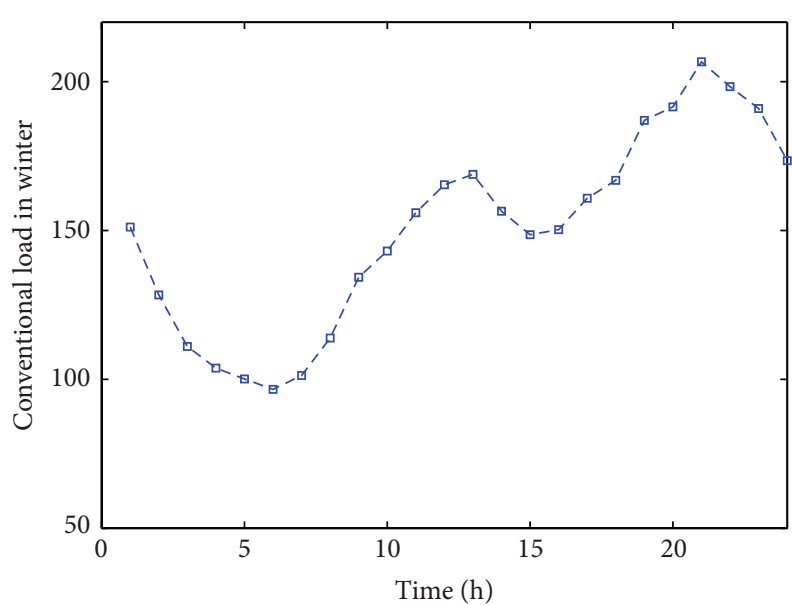

(a)

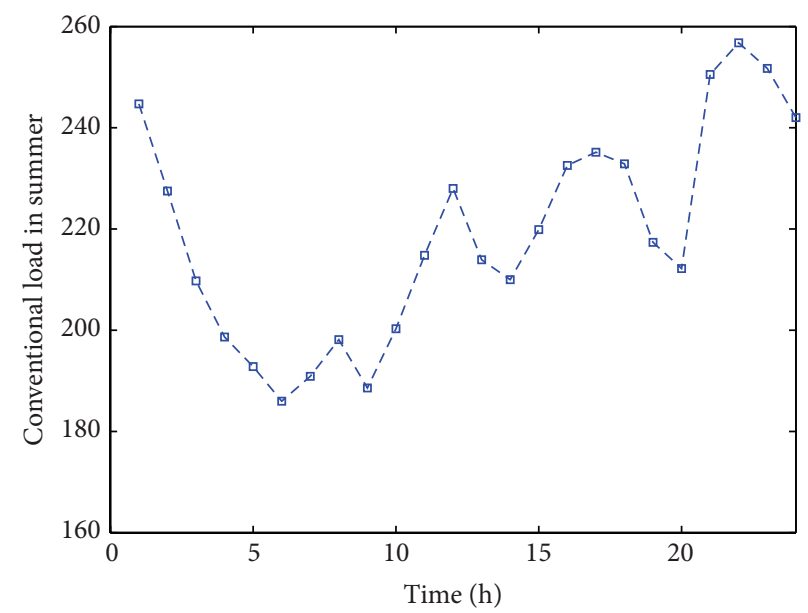

(b)

FIGURE 7: The conventional load in winter and summer.

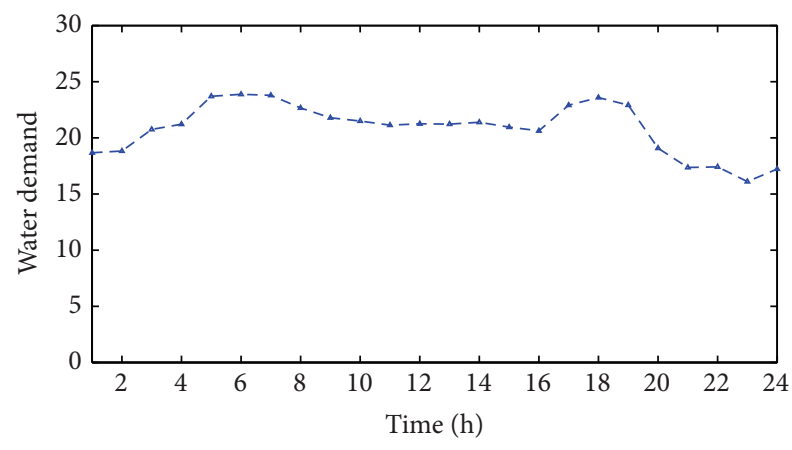

FIGURE 8: The daily water demand condition.

In Figure 9, it can be seen that from 1:00 a.m. to 2:00 a.m., the difference of conventional load and the output of renewable energy is small and is in the allowed battery discharging range, so the difference of net load is filled up by the storage battery firstly. At 4:00 a.m. and from 21:00 p.m. to 22:00 p.m., the output of renewable energy falls to the lowest value, and it has great vacancy of net load. The all discharging power of batteries cannot balance the power supply and demand. The diesel generators would be started to supplement the vacancy of net load. From 12:00 a.m. to 14:00 p.m., the output

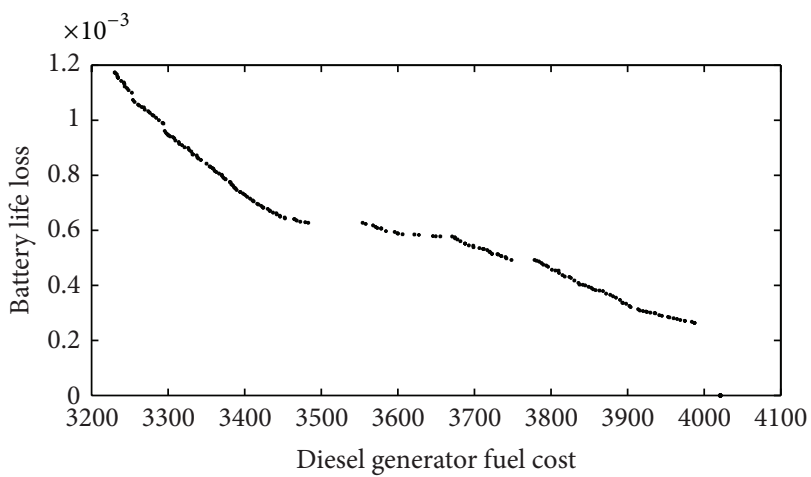

Figure 9: The result of Pareto front considering the effect of auxiliary power regulation.

of renewable energy reaches peak point, all the seawater desalination units are started in order to consume renewable energy as much as possible. Batteries and diesel generators are shut down at the same time. At 15:00 p.m., the seawater desalination system is working as auxiliary power regulation when the renewable energy output is low. The seawater desalination units are turned on as few as possible to meet the need of the basic water requirements of residents. 


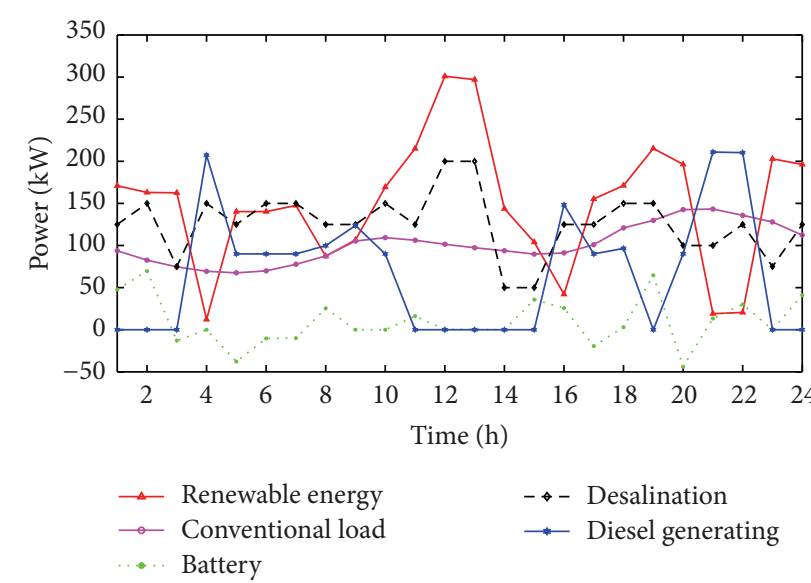

Figure 10: The output results of the various microsources in 24 hours without auxiliary power regulation at the least total loss expenses conditions.

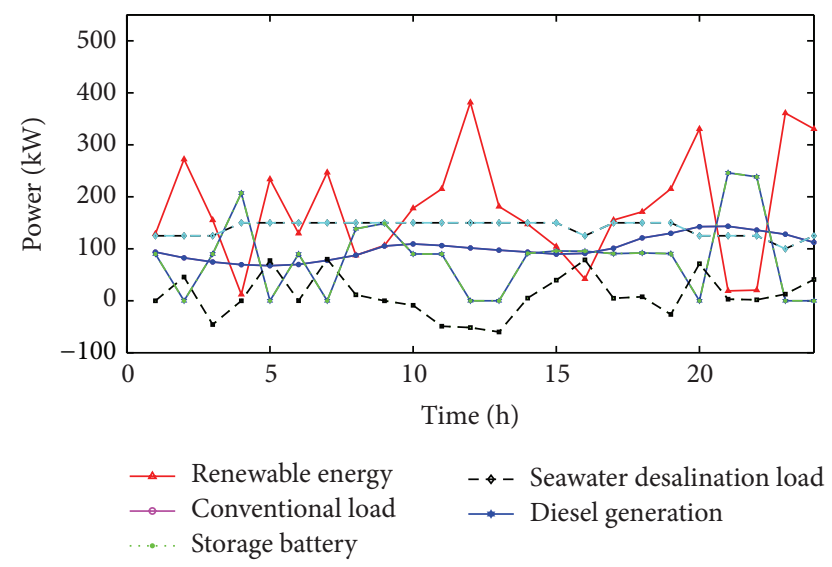

FIGURE 11: The output results of the various microsources in 24 hours without auxiliary power regulation at the least total loss expenses conditions.

Figure 10 shows the output results of the various microsources in 24 hours without auxiliary power regulation at the least total loss expenses conditions. Comparing with Table 3 , both the life loss of batteries and the fuel cost of diesel generators increase. The maximum of life loss adds by 0.0003 compared with the situation which considers auxiliary power regulation. The minimum and the maximum of fuel cost add by $694 \mathrm{RMB}$ and $486 \mathrm{RMB}$; economic efficiency of the overall optimization results is greatly affected due to the loss of seawater desalination auxiliary power regulation.

Figure 11 shows the SOC of storage batteries at the minimum of total loss expenses in 24 hours. At 23:00 p.m., SOC reaches the daily lowest value which is about 0.34 and the value satisfies the SOC constraint. The variation of production capacity, water storage capacity, and water demand to seawater desalination system is shown in Figure 12. The storage capacity keeps slightly higher than the minimum level in the majority of time, and it reaches the peak only at 14:00 p.m.. The reason is that the renewable energy output is

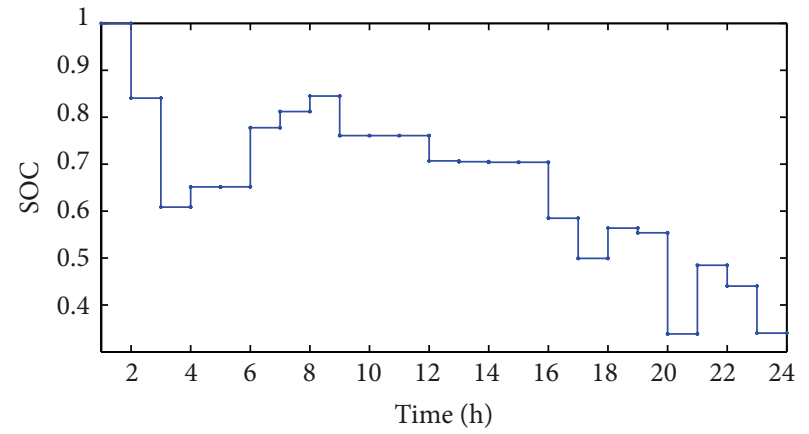

FIGURE 12: SOC of storage battery at the least total loss expenses condition in 24 hours.

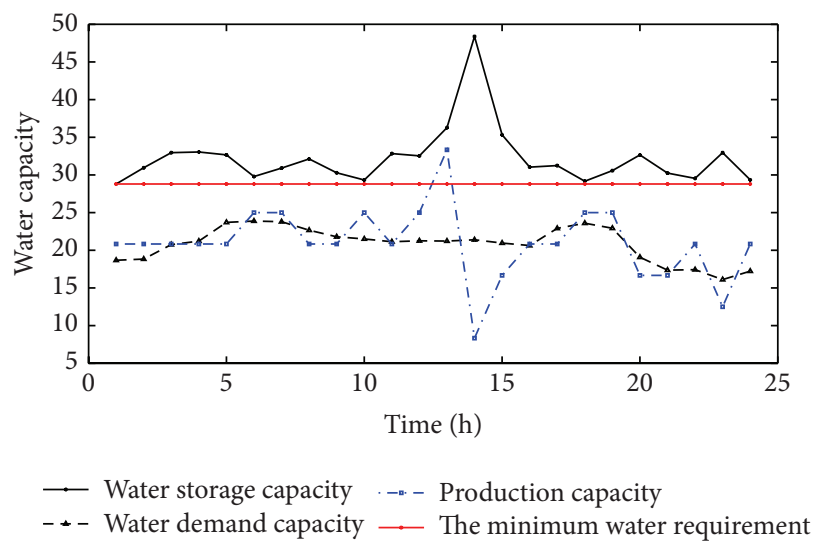

FIGURE 13: Water capacity of the seawater desalination system in 24 hours.

more than needed at 12:00 a.m.. All the seawater desalination units are used to consume surplus energy which results in production increasing. Furthermore, the amount of the minimum water requirement is 1.5 times that of the water demand capacity per hour, which ensures enough water to maintain the production and life in case the island suffers a blackout (Figure 13).

\section{Conclusion}

For the island microgrid with wind/photovoltaic/diesel/storage and seawater desalination load, a multiobjective optimization model and its solving method have been proposed. The controllable sources such as the seawater desalination load, storage batteries, and diesel generators have been taken into consideration and the power allocation strategy is proposed. The model is analyzed by solving a problem on a practical island, and the rationality of the proposed model and the power allocation strategy is verified.

During the process of practical island microgrid optimization, according to the project owner's specific investment requirement and generation proportion of renewable energy, the optimal solution method can be applied in the island microgrid. The theory evidence and technical support of the 
island microgrid optimal operation can be provided through the method.

\section{Conflict of Interests}

The authors declare that there is no conflict of interests regarding the publication of this paper.

\section{Acknowledgments}

This work is supported by the National Natural Science Foundation of China (no. 51277067) and the Project of Capital SCI \& TEC Resources Platform (no. Z131110000613053).

\section{References}

[1] B. Zhao, X. Zhang, P. Li et al., "Optimal sizing, operating strategy and operational experience of a stand-alone microgrid on Dongfushan Island," Applied Energy, vol. 113, pp. 1656-1666, 2014.

[2] R. M. Kamel, "Employing two novel mechanical fault ride through controllers for keeping stability of fixed speed wind generation systems hosted by standalone micro-grid," Applied Energy, vol. 116, pp. 398-408, 2014.

[3] G. P. Giatrakos, T. D. Tsoutsos, P. G. Mouchtaropoulos, G. D. Naxakis, and G. Stavrakakis, "Sustainable energy planning based on a stand-alone hybrid renewableenergy/hydrogen power system: application in Karpathos island, Greece," Renewable Energy, vol. 34, no. 12, pp. 2562-2570, 2009.

[4] K. Bourouni, T. Ben M’Barek, and A. Al Taee, "Design and optimization of desalination reverse osmosis plants driven by renewable energies using genetic algorithms," Renewable Energy, vol. 36, no. 3, pp. 936-950, 2011.

[5] E. Koutroulis and D. Kolokotsa, "Design optimization of desalination systems power-supplied by PV and W/G energy sources," Desalination, vol. 258, no. 1-3, pp. 171-181, 2010.

[6] S. Obara, S. Watanabe, and B. Rengarajan, "Operation method study based on the energy balance of an independent microgrid using solar-powered water electrolyzer and an electric heat pump," Energy, vol. 36, no. 8, pp. 5200-5213, 2011.

[7] J. Chen, C. Wang, B. Zhao, X. Zhang, and X. Ge, "Optimal sizing for stand-alone microgrid considering different control strategies," Automation of Electric Power Systems, vol. 37, no. 11, pp. 1-6, 2013.

[8] J. Chen, C. Wang, B. Zhao, and X. Zhang, "Economic operation optimization of a stand-alone microgrid system considering characteristics of energy storage system," Automation of Electric Power Systems, vol. 36, no. 20, pp. 25-31, 2012.

[9] M. Liu, C. Wang, L. Guo, B. Zhao, X. Zhang, and Y. Liu, "An optimal design method of multi-objective based island microgrid," Automation of Electric Power Systems, vol. 36, no. 17, pp. 34-39, 2012.

[10] G. Carpinelli, P. Caramia, F. Mottola et al., "Exponential weighted method and a compromise programming method for multi-objective operation of plug-in vehicle aggregators in microgrids," International Journal of Electrical Power and Energy Systems, vol. 56, pp. 374-384, 2014.

[11] M. Liu, C. Wang, L. Guo, B. Zhao, X. Zhang, and Y. Liu, "An optimal design method of multi-objective based island microgrid," Automation of Electric Power Systems, vol. 36, no. 17, pp. 34-39, 2010.
[12] S. Ozdemir, N. Altin, and I. Sefa, "Single stage three level grid interactive MPPT inverter for PV systems," Energy Conversion and Management, vol. 80, pp. 561-572, 2014.

[13] A. M. Eltamaly and H. M. Farh, "Maximum power extraction from wind energy system based on fuzzy logic control," Electric Power Systems Research, vol. 97, pp. 144-150, 2013.

[14] B. Bahmani-Firouzi and R. Azizipanah-Abarghooee, "Optimal sizing of battery energy storage for micro-grid operation management using a new improved bat algorithm," International Journal of Electrical Power and Energy Systems, vol. 56, pp. 4254, 2014.

[15] A. Baziar and A. Kavousi-Fard, "Considering uncertainty in the optimal energy management of renewable micro-grids including storage devices," Renewable Energy, vol. 59, pp. 158166, 2013.

[16] C. Zhou, K. Qian, M. Allan, and W. Zhou, "Modeling of the cost of EV battery wear due to V2G application in power systems," IEEE Transactions on Energy Conversion, vol. 26, no. 4, pp. 10411050, 2011.

[17] M. Farina and P. Amato, "A fuzzy definition of "optimality" for many-criteria optimization problems," IEEE Transactions on Systems, Man, and Cybernetics A: Systems and Humans, vol. 34, no. 3, pp. 315-326, 2004. 


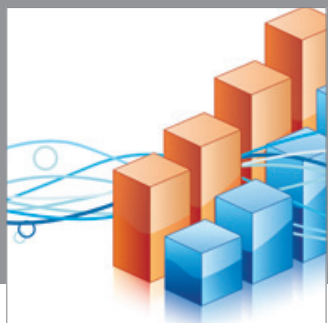

Advances in

Operations Research

mansans

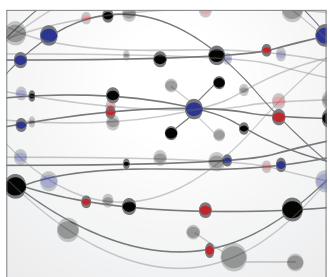

The Scientific World Journal
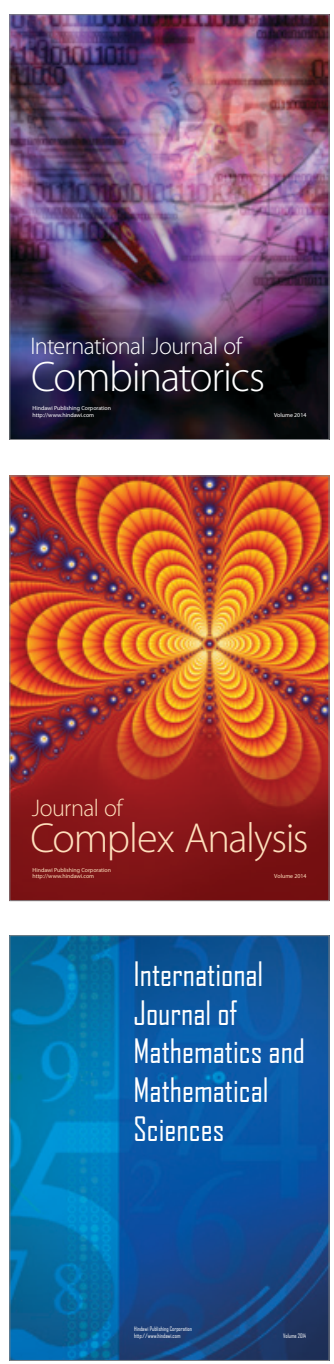
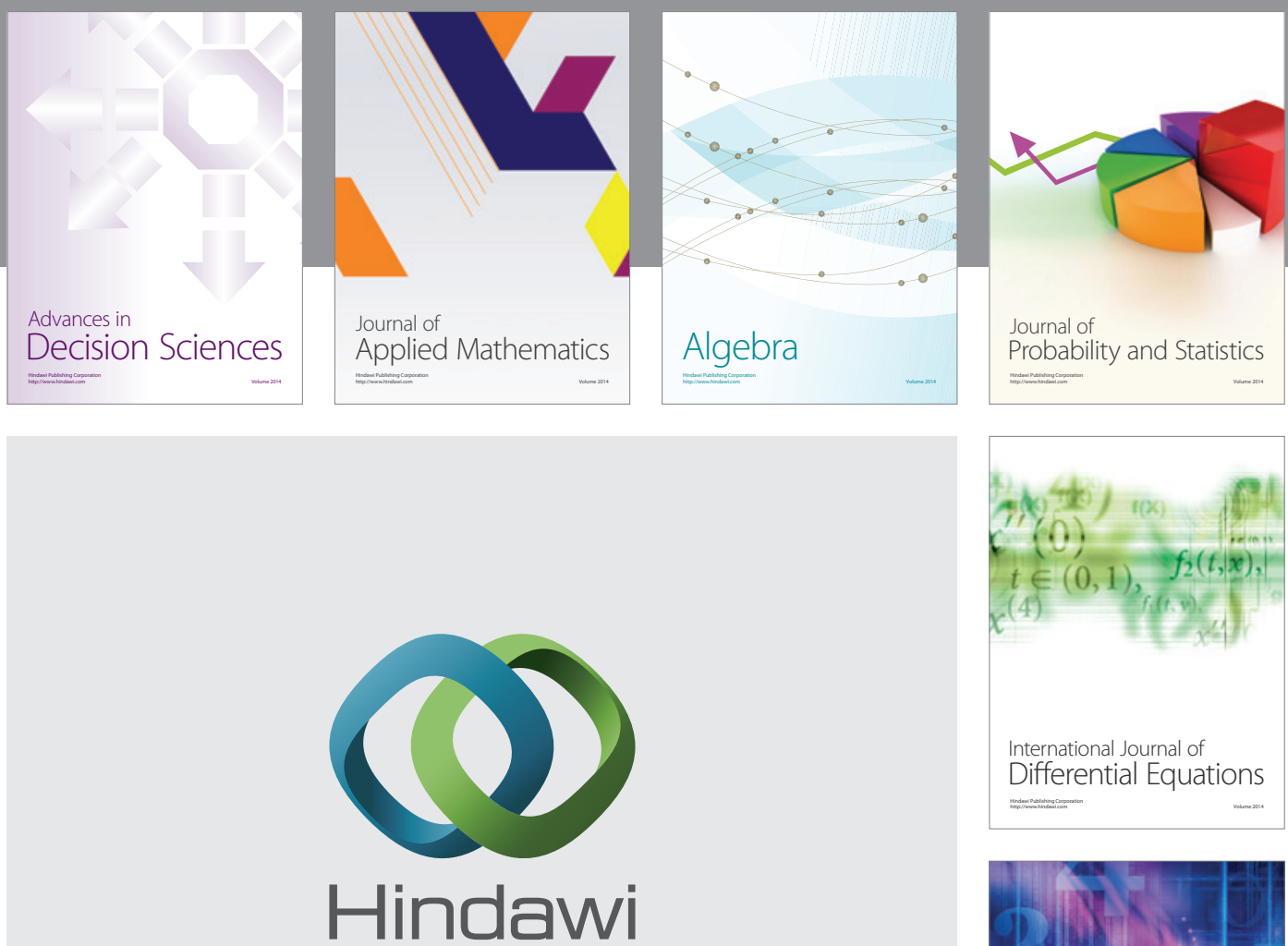

Submit your manuscripts at http://www.hindawi.com
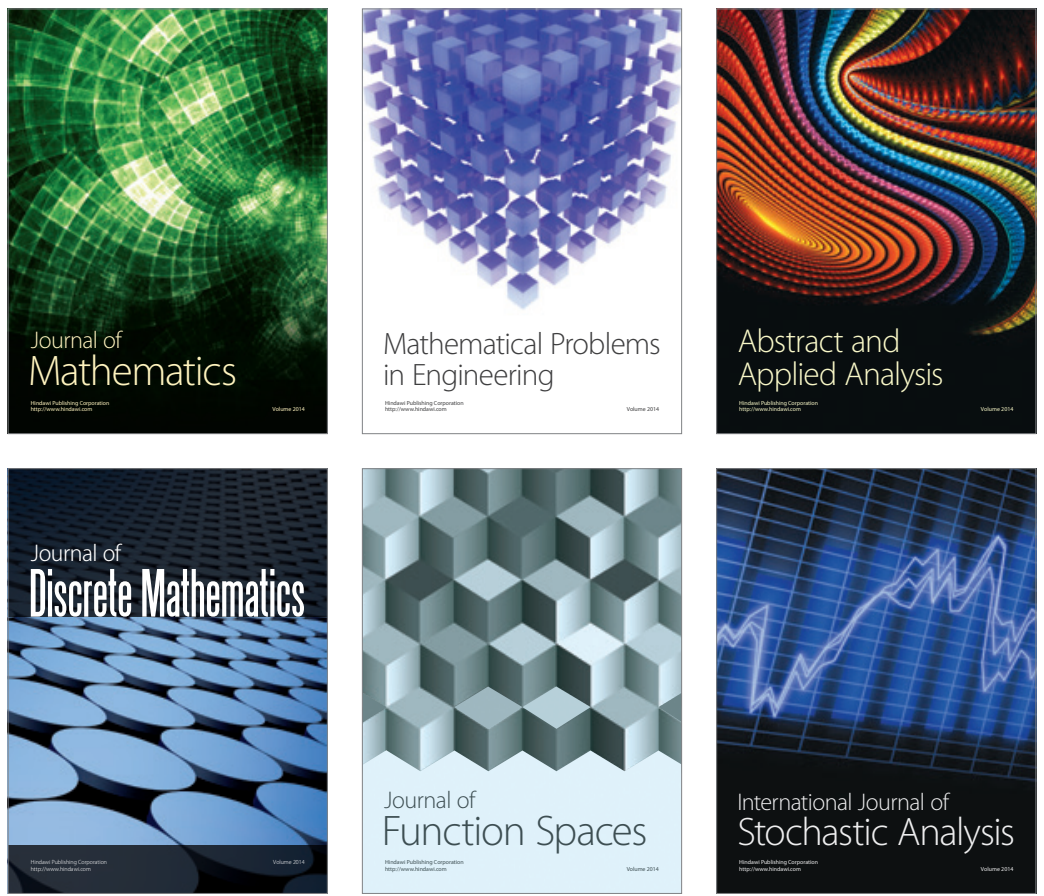

Journal of

Function Spaces

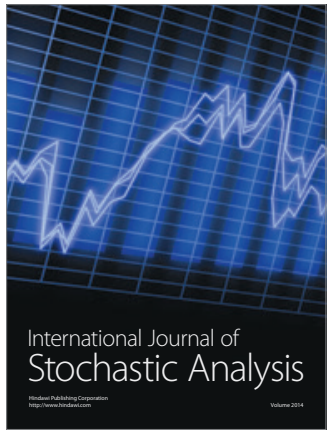

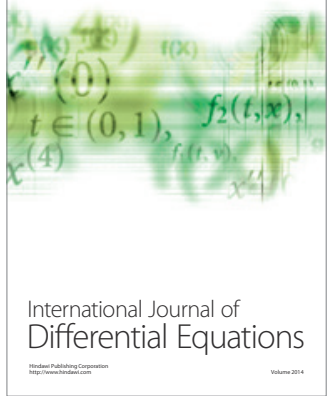
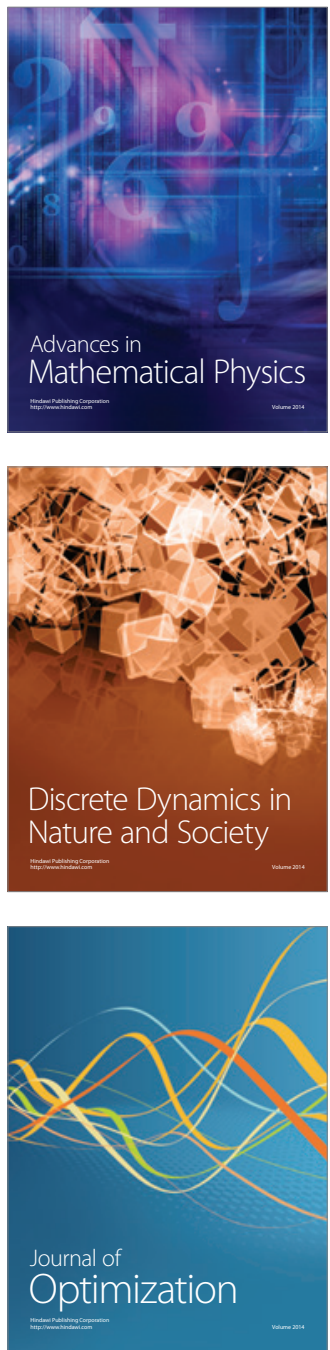